\title{
EFEITOS BIOLÓGICOS DA RADIAÇÃO ULTRAVIOLETA E SEU PAPEL NA CARCINOGÊNESE DE PELE: UMA REVISÃO
}

\author{
BIOLOGICAL EFFECTS OF ULTRAVIOLET RADIATION AND ITS ROLE IN
}

SKIN'S CARCINOGENESIS: A REVIEW

\section{Leandro Gonçalves Lopes}

Discente do curso de Tecnológico em Radiologia, Faculdade Evangélica de Ceres, Ceres-Go leandrog195@ hotmail.com

\section{Cláudio Ferreira de Sousa}

Discente do curso de Tecnológico em Radiologia, Faculdade Evangélica de Ceres, Ceres-Go claudioferreira2727@gmail.com

\section{Larisse Silva Dalla Libera}

Discente de doutorado em Ciências da Saúde, Mestre em Ciências da Saúde, Pós graduada em Metodologias para Ensino Superior, Biomédica e Orientadora e docente da Faculdade Evangélica de Ceres. Ceres-Go.

larisse.dalla@gmail.com

\section{RESUMO}

Introdução: Os raios ultravioletas são espectros de radiações eletromagnéticas emitidas pelo sol, que são divididos em três comprimentos de ondas UVA, UVB e UVC. Esses raios em contato com a pele humana desencadeiam diversas alterações, desde queimaduras solar ao desenvolvimento de uma lesão neoplásica como o câncer de pele não melanoma que é o câncer mais prevalente no Brasil e no mundo. Objetivo: abordar os principais efeitos da Radiação Ultravioleta (RUV) na carcinogênese de pele, bem como a prevalência e fatores de risco associados ao câncer de pele não melanoma. Metodologia: Trata-se de uma revisão narrativa descritiva, realizada nas bases de dados SCIELO, BVS e PUBMED, no período de agosto a outubro de 2017. Para cada estudo incluído foram extraídos autor; periódico; ano de publicação, tipo de estudo e principais resultados. Resultados e discussão: No processo de pesquisa e seleção foram encontrados 766 artigos, destes, 21 foram inclusos. A exposição a RUV solar ainda é o principal fator de risco para o câncer de pele não melanoma. No Brasil, REFACER v. 6, n. 2, 2017. ISSN - 2317-1367 
as Regiões Sul e Sudeste apresentaram os maiores índices de novos casos de câncer de pele não melanoma. Os indivíduos com pele clara ou branca foram os mais susceptíveis a exposição UV. Conclusão: A RUV tem papel fundamental na carcinogênese de pele do tipo não melanoma. A maior prevalência deste câncer é em pessoas de pele clara ou branca. Medidas de foto educação e fotoproteção ainda são necessárias.

Palavras chaves: Radiação ultravioleta; Câncer de pele; Não melanoma.

\begin{abstract}
Introduction: Ultraviolet rays are electromagnetic spectral radiation emitted by the sun, which is divided into three wavelengths of UVA, UVB and UVC. These rays in contact with human skin trigger several changes, from a sunburn up to development of a neoplastic lesion such as non-melanoma skin cancer which is Brazil and the world's most prevalent cancer. Objective: To address the main effects of ultraviolet radiation (UVR) on skin's carcinogenesis, as well as the prevalence and risk factors associated with non-melanoma skin cancer. Methodology: This is an exploratory narrative review, carried out in the SCIELO, VHL and PUBMED databases, from August to October 2017. For each included study, authors were extracted; newspaper; year of publication, type of study and main results. Results and discussion: In the process of research and selection, 766 articles were found, of which 21 were included. Exposure to solar RUV is still the main risk factor for nonmelanoma skin cancer. In Brazil, the South and Southeast Regions presented the highest rates of new cases of non-melanoma skin cancer. Individuals with light or white skin were the most susceptible to UV danger. Conclusion: RUV plays a key role in non-melanoma skin carcinogenesis. The highest predominance of this cancer is in people with light or white skin. Measures of photo-education and photoprotection still seem to be necessary.
\end{abstract}

Keywords: Ultraviolet radiation; Skin cancer; Non-melanoma.

\title{
INTRODUÇÃO
}

Os raios ultravioletas (UV) são radiações emitidas pelo sol e compreendem de $3 \%$ a 5\% de toda radiação solar que penetra a superfície terrestre. Essa radiação alcança a terra em forma de ondas eletromagnética muito curta, sendo invisível aos nossos olhos por apresentar 
espectros de comprimento de ondas, entre 200 e 400 nanômetros (nm). Esses espectros são divididos em três comprimentos de onda: UVC (200 a 280nm), UVB (280 a 320 nm) e UVA (320 a 400nm) (ROBBINS; COTRAN; KUMAR, 2005).

A população é diariamente exposta à Radiação Ultravioleta (RUV), principalmente quando não protegida por vestimentas grossas e protetores químicos UV. Essa exposição gera desde danos mais leves, como as mudanças degenerativas na elastina e no colágeno da pele do indivíduo, assim como, enrugamento, frouxidão e aparência envelhecida da pela, até mudanças mais severas, como queimaduras, inflamações, mutações genéticas e o câncer de pele (SILVA, 2007).

Uma vez que essa radiação é absorvida pelas células da epiderme e derme, mais especificamente a melanina, causam reações nas bases das moléculas de DNA e RNA da célula, alterando sua estrutura original e consequentemente sua função. $\mathrm{O}$ acúmulo sucessivo de erros no material genético e sua replicação desordenada pelas células do tecido, levam ao desenvolvimento de lesões benignas que se não tratadas ou identificadas a tempo, podem evoluir para o câncer (BALOGH et al., 2011).

Um dos fatores de risco que mais levam a carcinogênese de pele, principalmente do câncer de pele do tipo não melanoma é a exposição prolongada e repetida à radiação ultravioleta solar. Cerca de $90 \%$ das lesões localizam-se nas áreas da pele que ficam mais expostas ao sol, demonstrando a importância dessa exposição para o surgimento do tumor. Os indivíduos mais atingidos pelo câncer de pele são principalmente as pessoas de pele branca, que possuem pouca melanina e que nunca se bronzeiam ou se bronzeiam com dificuldade (CEONI, 2009).

O câncer de pele não melanoma corresponde a 30\% de todos os tumores malignos registrados no Brasil. Em 2016 foram estimados 175.760 novos casos de câncer de pele não melanoma no país, sendo 80.850 em homens e 94.910 em mulheres. Esses valores correspondem a um risco estimado de 81,66 casos novos a cada 100 mil homens e 91,98 a cada 100 mil mulheres. Na região Centro-Oeste estima-se 16.350 novos casos de câncer de pele não melanoma, só no estado de Goiás o total de novos casos é de 7.750, sendo que 4.050 em homens e 3.700 em mulheres (BRASIL, 2015).

A radiação ultravioleta tem papel fundamental no desenvolvimento do câncer de pele não melanoma. Neste contexto, o presente estudo tem por objetivo abordar os principais efeitos da RUV na carcinogênese de pele, bem como a prevalência e fatores de risco 
associados ao câncer de pele não melanoma. Desta forma é possível expor os principais meios de fotoproteção e estratégias que poderão minimizar os efeitos a longo prazo da RUV.

\section{METODOLOGIA}

Trata-se de uma revisão da literatura do tipo narrativa descritiva para analisar o papel da exposição humana à radiação ultravioleta solar e o desenvolvimento do câncer de pele não melanoma. A busca foi realizada nos meses de agosto a outubro de 2017 por dois pesquisadores. Foram feitas a delimitação do tema de interesse, dos critérios de inclusão e exclusão, as estratégias de busca e seleção, tal como os autores também elaboram um formulário para obtenção dos dados e subsequente análise e interpretação dos resultados.

Para coleta e seleção dos dados científicos, os principais buscadores e bases de dados foram consultados, como: Google Acadêmico; Biblioteca Virtual em Saúde (BVS); Scientific Eletronic Library Online (SCIELO) e, National Center for Biotechnology Information, U.S. National Library of Medicine (PUBMED). Também foram acrecidos dados do Instituto Nacional do Câncer (INCA) e Instituto Brasileiro de Geografia e Estatística (IBGE), como fonte adicional de dados para as características sociodemográficas e estatísticas de câncer de pele não melanoma.

Foram incluídas produções disponíveis em língua Portuguesa e Inglesa no período de 2008 a 2018, que abordavam a temática sob perspectiva científica. Também foram utilizados descritores DECS e MESH que estão citados abaixo. A abordagem dos textos incluídos no trabalho, enfatizavam especificamente a radiação ultravioleta e o câncer de pele não melanoma.

Para descrever a prevalência do câncer de pele não melanoma e as características da população brasileira, os dados do INCA e IBGE foram utilizados. Os dados coletados no INCA referiram-se à prevalência de câncer de pele não melanoma por região, estado e cidade, enquanto os dados do IBGE referiram-se à população geral, sua idade, sexo e etnia. Para cada estudo incluído foram extraídos autor; periódico; ano de publicação; tipo de estudo; objetivo e principais resultados.

Embora o trabalho seja coletivo, optou-se por proceder na pesquisa de artigos de modo individual. Os autores estabeleceram buscas independentes que, posteriormente, foram agrupadas e selecionadas conforme o consenso geral. Para tanto, o uso dos descritores listados no "DECS e MESH" foram determinados, tal como os termos usados no Google Acadêmico: 
"radiação ultravioleta", "exposição solar", "câncer de pele", "tumor cutâneo", "tumores cutâneos", "não melanoma", "carcinoma", "carcinogênese". Já para a plataforma Scielo a locução "(radiação ultravioleta) AND (câncer de pele) OR (tumor cutâneo)" foi adotada. Na BVS foi utilizado "(câncer de pele) OR (tumor cutâneo) OR (tumores de pele) AND (radiação ultravioleta) AND (proteção)". Para a plataforma PUBMED adotou-se o uso de MESH, (skin cancer) OR (skin tumor) OR (skin tumor) AND (ultraviolet radiation) AND (protection) AND (not-melanoma).

Também foram consultadas as referências dos artigos incluídos, para agrupar o maior número de artigos sobre o tema. As duplicatas encontradas durante a busca, foram eliminadas manualmente. Por fim, visando transparência e objetividade na exposição do conteúdo produzido, o papel da radiação ultravioleta no câncer de pele não melanoma foi apresentado e discutido em sub tópicos. Ao final do trabalho, o apêndice 1 traz as características dos estudos incluídos para consulta complementar.

\section{RESULTADOS E DISCUSSÃO}

No processo de pesquisa e seleção foram encontrados 766 artigos, destes, apenas

21 foram inclusos (figura 1; apêndice 1). Todos os trabalhos retrataram sobre radiações UV, os tipos de patologias que podem se desenvolver pela exposição solar e a carcinogênese de pele. Também foram expostos os principais fatores de risco da população e a prevalência do câncer de pele não melanoma (tabela 1 e 2).

\section{Características da Radiação Ultravioleta}

A radiação ultravioleta é uma radiação eletromagnética que tem como fonte natural o sol. Outras fontes principais de RUV são as artificiais, como: lâmpadas, germicidas, equipamentos para solda industrial de metal ou mesmo as lâmpadas negras (OKUNO; VILELA, 2005).

Para gerar dano ao ser humano, a intensidade da radiação ultravioleta e seu comprimento de onda dependem de alguns fatores, como: altitude, latitude, estação do ano, horário e condições atmosféricas. A ozonosfera é uma das principais barreiras de proteção aos 
raios ultravioletas. Sua destruição por produtos químicos exalados no ar durante os últimos anos aumentaram o poder de penetração dos raios UV (GROFF, 2008).

Um aspecto interessante do estudo das RUV é a relação direta dos seus malefícios com à posição geográfica avaliada. Por exemplo, na linha do Equador a quantidade de raios UV absorvidos pelo indivíduo será bem maior, se comparada com regiões mais distantes. A altitude do local também interfere na quantidade de raios solares, já que regiões a nível do mar apresentam menor quantidade de ozônio. Em locais arenosos o fluxo ou a porcentagem da radiação UV tende a ser grande pelo tipo de superfície, presença de água, neve ou areia, isso faz com que os raios sejam refletidos. A nebulosidade também interfere na irradiância, mas isso depende de fatores e características de cada nuvem, perfil e densidade (SILVA; OGAWA; SOUZA, 2017).

A radiação UV apresenta diferentes espectros de raios eletromagnéticos. Esses raios, espalham-se por inúmeras extensões de ondas com distintas intensidades de radiância e que na maioria das vezes são nocivas (SILVA, 2007). Como a radiação UV possui três principais espectros de comprimento de ondas (entre 200 e $400 \mathrm{~nm}$ ), cada espectro será responsável por um tipo específico de intensidade da radiação e consequentemente de dano aos organismos vivos. Os três principais comprimentos de onda são UVC (200 a 280nm), UVB (280 a 320 nm) e UVA (320 a 400nm) (OKUNO; VILELA, 2005).

A radiação UVA é conhecida como luz negra ou fluorescente, ela representa 90\% a 95\% da radiação ultravioleta. Nada pode absorvê-la, de maneira que sua radiação chega normalmente à superfície terrestre. Os efeitos são de pequena duração e reversíveis. Seus raios segundo Robbins, Contran, Kumar (2005, p. 461) levam a pigmentação da pele e a oxidação da melanina, que apesar de ser passageira, induz o escurecimento imediato da pele, especialmente em indivíduos de pele mais escura, já que eles possuem um número maior de melanócitos.

A radiação UVA ainda é subdividida em UVA- I (340 a 400 nm) e UVA-II (315 a $340 \mathrm{~nm}$ ). A radiação UVA-I possui maior capacidade de penetração na pele, com alto potencial para causar danos na estrutura do DNA e induzir ao câncer cutâneo. A radiação UVA-II assemelha-se à radiação UVB e sua superexposição pode causar eritema, câncer de pele e afetar o sistema imunológico (OKUNO; VILELA, 2005).

REFACER v. 6, n. 2, 2017. ISSN - 2317-1367 
A radiação UVA por ter um comprimento de onda maior, tem uma relevância de menor quantidade energética, por isso os possíveis eritemas gerados na pele, são menores em relação aos raios UVB. Essa característica faz com que ela chegue com maior facilidade e alcance a derme, ocasionando pigmentação da pele, provocando o efeito de bronzeado pelo escurecimento da melanina em um processo de foto oxidação da leucomelanina (SILVA; OGAWA; SOUZA, 2017).

A radiação UVB é denominada de luz eritematogênica, um de seus papeis mais conhecidos é a sua influência na síntese endógena de vitamina D a partir do colesterol. Contudo, a radiação UVB, também pode ser responsável por lesões crônicas na pele, como eritema, edema, escurecimento do pigmento, espessamento da derme e epiderme, catarata, supressão no sistema imunológico e mutações gênicas que levam ao câncer de pele (ROBBINS; COTRAN; KUMAR, 2005).

Apenas 5 a $10 \%$ dos raios UVB atingem a superfície terrestre e são retidos na camada de ozônio, principalmente no período do verão que tem maior incidência de raios. A UVB é mais intensa entre 10 e 16 horas, sendo aconselhável evitar exposições solares neste período. Como seu comprimento de onda é menor, a UVB penetra mais superficialmente na pele (ROBBINS; COTRAN; KUMAR, 2005).

Os raios UVB proporciona maior risco para o desencadeamento das neoplasias cutâneas. Por se tratar de uma dose cumulativa, aparenta ser uma das causas mais consideráveis de indução a carcinogênese de pele do tipo não melanoma (KÜTTING; DREXLER, 2010).

A radiação UVC tem o menor comprimento de onda e é a mais energética das radiações. Como sua capacidade de penetração é maior, há um maior risco biológico para quem é exposto. Por se tratar de uma radiação de onda curta ela é mais absorvida pela camada de ozônio chegando à superfície terrestre em pequenas quantidades (SILVA; OGAWA; SOUZA, 2017).

\section{Efeitos Danosos da Radiação Ultravioleta}


A pele é o maior órgão do corpo humano, atuando como a principal barreira contra a radiação ultravioleta. Contudo, as camadas da epiderme e derme são as mais relevantes, pois sofre ação direta dos efeitos fotobiológicos da radiação UV (MESAARANGO; FLÓREZ-MUÑOZ; SANCLEMENTE, 2017).

A interação dos raios UV e as consequentes alterações na pele humana, estão amplamente relacionadas com as diferentes reações químicas e morfológicas geradas nas células. Os efeitos clínicos, principalmente os de origem UVB, podem ser considerados agudos ou crônicos de acordo com essas mudanças (SGARBI; CARMO; ROSA, 2007).

A exposição aguda gera alterações na epiderme, pigmentação excessiva, desencadeamento de processos inflamatórios, aumento da temperatura da pele, eritemas, espessamento da camada espinhosa, ulcerações, pigmentação e supressão da imunidade adquirida. Essas alterações interferem no papel protetor da pele, acarretando com o tempo, efeitos crônicos, como a fotocarcinogênese e o fotoenvelhecimento da pele (SGARBI; CARMO; ROSA, 2007; SCHALKA et al., 2014; YOUNG; CLAVEAU; ROSSI, 2016).

Essa exposição da pele aos raios UV, inicia uma variedade de respostas celulares que resultam em inúmeros danos a nível molecular (MESA-ARANGO; FLÓREZ-MUÑOZ; SANCLEMENTE, 2017). Como o DNA é altamente cumulativo de radiação UV, as alterações químicas provocadas por essa exposição levam a mutações irreversíveis e recorrentes com o tempo (MESA-ARANGO; FLÓREZ-MUÑOZ; SANCLEMENTE, 2017).

A radiação de faixa espectral UVB, atua diretamente no desenvolvimento de dímeros de ciclobutano, pirimidinas e foto produtos. Essas alterações causam distúrbios de replicação e diferenciamento celular, principalmente pelas modificações no gene codificante para a proteína de supressão tumoral p53. As disfunções moleculares envolvidas, geram mudanças não naturais e muitas vezes irreversíveis aos queratinócitos e melanócitos que ocasionalmente leva ao aparecimento de tumores de pele (SGARBI; CARMO; ROSA, 2007; RODRIGUES; MARTIN; MORAES, 2016).

Na faixa espectral da UVA, a RUV indiretamente incita a produção de processos oxidativos e radicais livres. O aumento dos processos referentes ao oxigênio é possivelmente um dos fenômenos mais relevantes posteriormente a exposição ao sol, pois proporciona modificações celulares e mutações no DNA presente no núcleo e nas mitocôndrias. Isso ocasiona modificações nas bases nitrogenadas do tipo guanina, rupturas nas cadeias simples e nas pirimidinas oxidadas (MESA-ARANGO; FLÓREZ-MUÑOZ; SANCLEMENTE, 2017). 
As mitocôndrias produzem adenosina trifosfato (ATP) que serve como energia para a célula. Os raios UVA provocam a mutação do DNA mitocondrial, diminuindo o funcionamento e produção das mitocôndrias, interferindo no fornecimento de energia para a célula. Possivelmente todas essas alterações provocadas pela radiação desencadeiam o câncer de pele. Mesmo com baixa exposição aos raios UVB pode haver desenvolvimento de lesões neoplásicas, isso porque o DNA tem capacidade cumulativa de radiação e consequentemente de mutações (SGARBI; CARMO; ROSA, 2007).

As bases pirimídicas citosina e guanina $(\mathrm{C}-\mathrm{G})$ do DNA são mais susceptíveis a sofrerem alterações pela radiação. No câncer de pele a citosina $(\mathrm{C})$ é trocada por uma timina (T), quando está próxima de $\mathrm{T}$ ou $\mathrm{C}$, observa-se que só é considerada mutação se as substituições das bases também estiverem nas células filhas. (JUNQUEIRA; CARNEIRO, 2012).

Outra alteração molecular crítica que é desencadeada pela exposição a RUV é o rompimento da dupla hélice do DNA. A mudança na composição da molécula de DNA, altera sua função a ponto de bloquear a replicação e impedir a transcrição gênica. Com isso, a célula pode tentar reparar o dano e voltar a seu funcionamento normal, entrar em apoptose e ser eliminada do tecido, ou continuar a divisão celular mesmo com o DNA modificado e perder suas características iniciais a ponto de se tornar uma célula neoplásica maligna (YOUNG; CLAVEAU; ROSSI, 2016).

Os sinais e sintomas do câncer de pele podem surgir a partir da pele normal ou de uma lesão pigmentada. A manifestação da doença na pele normal se dá após o aparecimento de uma pinta escura de bordas irregulares acompanhada de coceira, descamação, ardência e pela presença de feridas na pele cuja cicatrização demore mais de quatro semanas. Em casos de uma lesão pigmentada preexistente ocorre aumento no tamanho, alteração na coloração e na forma da lesão, que passa a apresentar bordas irregulares (BRASIL, 2017).

O câncer é uma neoplasia maligna que tem origens diferentes, porque tem formações celulares distintas. A pele naturalmente tem seu processo de diferenciação celular, o câncer de pele ocorre geralmente nas células da epiderme e derme, sendo subdivididos em câncer do tipo melanoma cutâneo e câncer cutâneo do tipo não melanoma como o carcinoma basocelular (CBC) e o carcinoma espinocelular (CEC) (RODRIGUES; MARTIN; MORAES, 2016).

A maior incidência de tumores de pele é do tipo não melanoma, pelo fato deste tecido estar em constante renovação celular. Quanto maior o processo de replicação celular 
maior o número de mutações geradas pelas falhas da síntese de uma nova molécula de DNA. Sendo a pele o principal revestimento da superfície corporal, a radiação ultravioleta solar age como agente cancerígeno causal do câncer de pele do tipo não melanoma (JUNQUEIRA; CARNEIRO, 2012).

Os carcinomas CBC e CEC ocorrem principalmente na população caucasiana, por exposição exagerada ao sol. Essas neoplasias são induzidas por elevadas doses de raios solares descontínuos que geram queimaduras e também estão associados à exposição ocupacional (CEZAR-VAZ et al., 2015).

Os tumores não melanomas desenvolvem-se principalmente na região da cabeça $\mathrm{e}$ pescoço, que são áreas mais expostas ao sol e de maior sensibilidade. Surgem como nódulos, transparentes e isolados e não apresenta nenhum sintoma. Estes tumores têm capacidade metastática baixa em todos os tipos de peles e são de fácil tratamento por excisão cirúrgica, quando diagnosticados precocemente (CHINEM; MIOT, 2011; AGBAI et al., 2014).

\section{Prevalência do câncer de pele não melanoma}

O câncer de pele é a neoplasia maligna mais comum em humanos no mundo, principalmente em caucasianos. No Brasil o câncer de pele não melanoma representa $30 \%$ de todos os tumores malignos registrados (BRASIL, 2017). Esperam-se 80.850 casos novos de câncer de pele não melanoma nos homens e 94.910 nas mulheres no Brasil, em 2016 (tabela 1). Esses valores correspondem a um risco estimado de 81,66 casos novos a cada 100 mil homens e 91,98 para cada 100 mil mulheres. O câncer de pele não melanoma é o primeiro mais incidente em homens nas Regiões Sul (138,75/100 mil), Centro-Oeste (114,71/100 mil) e Sudeste (92,86/100 mil). Nas Regiões Nordeste (42,48/100 mil) e Norte (28,89/100 mil), encontram-se na segunda posição. Nas mulheres, é o mais frequente em quatro Regiões, com um risco estimado de 134,19/100 mil na Região Sudeste, 102,71/100 mil na Região CentroOeste, 93,58/100 mil na Região Sul e 44,12/100 mil na Região Nordeste. Já na Região Norte (23,12/100 mil), ocupa a segunda posição (BRASIL, 2015).

Estima-se que a exposição a RUV esteja associada a $65 \%$ dos canceres do tipo melanoma e 90\% de cânceres de pele não melanoma, incluindo carcinoma basocelular (CBC) e o carcinoma espinocelular (CEC). O carcinoma basocelular é mais predominante em caucasianos (em torno de 5\%). O risco cumulativo de desenvolvimento de CBC durante toda a vida da população branca alemã é em torno de 30\% (CHINEM; MIOT, 2011). 
O CEC corresponde a 10-20\% dos tumores de pele. Sua incidência aumenta com a idade e o sexo mais acometido é o masculino. Em geral, o CEC está associado ao acúmulo das doses de exposição ao sol, enquanto o CBC parece estar mais associado com a exposição intermitente para altas doses de radiação solar (BRASIL, 2017).

O CEC é o câncer de pele de maior prevalência e o segundo mais diagnosticado em pessoas de pele clara ou branca. Entre os fatores que influenciam para o desenvolvimento do CEC estão as inflamações, lúpus eritematoso, cicatrizes causadas por queimaduras químicas e térmicas, úlceras da pele e locais regularmente expostos ao sol (AGBAI et al., 2014).

Apesar da prevalência do câncer de pele não melanoma crescer em grupos etários mais jovens (KIM; YU-YING-HE, 2014), pessoas na média dos 50 anos ainda são as mais diagnosticadas com esse tipo de câncer, principalmente os canceres de pele do tipo basocelular (CASTILHO; SOUZA; LEITE, 2010; AGBAI et al., 2014).

Um estudo com trabalhadores rurais do Estado do Rio Grande do Sul revelou que esses trabalhadores estão mais propensos a desenvolver o câncer de pele pelo fato de estar em constante exposição ao sol durante sua jornada de trabalho, revelou também que as maiores incidências são em pessoas do sexo masculino com idade media, acima de cinquenta anos, caucasianos e com escolaridade incompleta. A pesquisa mostrou que a maioria dos entrevistados não tinha conhecimento em relação ao câncer de pele (CEZAR-VAZ et al., 2015).

O Brasil tem uma generosa oferta de raios UV, apresentando valores elevados em latitudes geográficas menores, em estações mais quentes, em determinados horários do dia e em diferentes condições meteorológicas. As regiões Norte e Nordeste por exemplo, apresentam maiores doses cumulativas de RUV do que nas regiões Sul e Sudeste em que o índice de UV sofre variação entre o inverno e o verão (SCHALKA et al., 2014).

\section{Fatores de risco para o câncer de pele não melanoma}

Os fatores de riscos para o desenvolvimento do câncer de pele apresentam diversas evidências clínicas e experimentais, como fatores imunológicos, imunossupressores, entre outros. A exposição prolongada ao sol ou a emissores de UV artificiais, as características fenotípicas como pele clara, olhos claros, cabelos claros ou ruivos, a presença de sardas na infância, idade avançada, a presença de doença autoimune ou sistema imune 
deprimido, são considerados fatores de risco para o câncer de pele do tipo não melanoma (NICHOLS; KATIYAR, 2009; MORGATTO et al., 2016).

Apesar dos indivíduos caucasianos apresentarem maior risco de câncer de pele não melanoma por RUV, o Brasil é conhecido pela sua miscigenação. O País apresenta diferentes etnias entre suas regiões (tabela 2). No Norte e Nordeste por exemplo, a prevalência da população de cor branca é menor em comparação com as regiões, Sul, Sudeste e Centro-Oeste.

As regiões do País com menor número de câncer de pele são também as que apresentam números maiores de pardos ou negros. Isso porque a pigmentação maior da pele, confere fator de proteção para esses indivíduos, já que como exposto, a melanina impede possíveis efeitos causados pela radiação ultravioleta se comparado as pessoas de pele clara ou branca que se queima com maior facilidade. (OLIVEIRA, 2013; BRITO et al., 2015).

O câncer de pele tem maior incidência na região Sul e Sudeste do país. Nestas regiões predominam a população de pele mais clara ou branca (BRASIL, 2015). Esses indivíduos são em sua maioria descendentes de europeus, particularmente de origem alemã e portuguesa. A maioria vive em ambientes de clima temperado e tropical e se dedicam as atividades e trabalhos rurais, principalmente na região Sul e Sudeste. A constante exposição ao sol, desde a infância até a fase adulta, expõe esses indivíduos aos riscos da RUV. A falta de informação ou cuidados básicos de prevenção contra o câncer de pele estão diretamente ligados com as questões socioeconômicas e culturais do país (OLIVEIRA, 2013; MORGATTO et al., 2016).

\section{Fotoproteção}

As medidas de fotoproteção proporcionam uma redução da exposição e levam a diminuição dos danos agudos e crônico da radiação ultravioleta. A fotoproteção depende da maior combinação de medidas possíveis, que levam em consideração o fenótipo da pessoa, os hábitos de vida, exposição profissional, localização geográfica e histórico de câncer de pele na família (SCHALKA et al., 2014).

Uma medida de fotoproteção é evitar a exposição ao sol durante horários de 10 a 16 horas, por se tratar de um período onde os raios solares são mais intensos. Um estudo realizado na população da cidade de Morro Redondo no Rio Grande do Sul, mostrou que as pessoas fazem uso de chapéus, óculos de sol e o uso de protetor solar que ajudam a barrar os efeitos dos raios UV (MORGATTO et al., 2016). No meio rural, o uso do protetor solar, o uso 
de luvas, hidratantes, macacões, camisa de manga comprida, também conferem fotoproteção (CEZAR-VAZ et al., 2015; BEZERRA et al., 2011).

O uso de vestimentas adequadas que não expõe a pele ao sol, óculos escuros e chapéus, são as formas mais acessíveis e eficazes para a proteção da pele contra a RUV. O uso de foto protetores solares é a principal forma de fotoproteção. Atualmente existe diversos tipos de protetores solares disponíveis, contudo, seu uso na população mais pobre é menos frequente porque seu valor de comercialização acaba não sendo acessível a essas pessoas (BALOGH et al., 2011).

As pessoas que estão em constante exposição ao sol especialmente as pessoas mais claras devem ficar atentas aos sinais e sintomas do câncer de pele, isso não quer dizer que as pessoas com maior pigmentação da pele não devem se preocupar. O diagnóstico precoce do câncer de pele juntamente com o rastreamento e a prevenção, proporciona um tratamento mais rápido, diminuem a morbidade e aumentam consideravelmente a sobrevida dos pacientes (RIZZATTI; SCHNEIDER; D'ORSI, 2011; MORGATTO et al., 2016).

O tratamento mais adequado é a cirurgia tanto nos casos de carcinoma basocelular como de carcinoma espinocelular. Portanto, o carcinoma basocelular de pequena extensão pode ser tratado com medicamento tópico ou radioterapia. No carcinoma espinocelular, o tratamento mais comum é a combinação de cirurgia e radioterapia (CHINEM; MIOT, 2011; INCA, 2017).

No Brasil o câncer de pele não melanoma é considerado um problema de saúde pública. Intervenções e campanhas de conscientização das medidas de proteção a exposição UV ainda precisam ser mais empregadas. As medidas de fotoproteção, como a utilização de protetores UV devem ser mais bem incorporadas a rotina do dia a dia, principalmente nas idades precoces. Infelizmente um dos maiores problemas enfrentados na adequação da fotoproteção ao estilo de vida é diferença socioeconômica da população e pela falta de informação. (IMANICHI et al., 2017).

\section{CONCLUSÃO}

A radiação ultravioleta tem papel fundamental no processo da carcinogênese da pele, principalmente nos canceres não melanomas do tipo basocelular e espinocelular. As diversas alterações no DNA das células da pele, como quebra de pontes de hidrogênio e troca de bases nitrogenadas geram mutações cumulativas, ocasionando com o tempo o câncer. 
O câncer de pele do tipo não melanoma ainda é o mais prevalente no País. A exposição a RUV solar ainda é o principal fator de risco para este câncer. No Brasil, apesar das regiões Norte e Nordeste serem mais afetadas pela radiação UV o Sul e Sudeste apresentaram os maiores índices de novos casos de câncer de pele não melanoma. Isso porque há maior concentração de indivíduos com pele clara ou branca que são mais susceptíveis a essa exposição.

O uso de vestimentas próprias e protetores UV conferem maior proteção a RUV, contudo, a falta de informação e a prolongada exposição ocupacional, estão diretamente ligadas ao desenvolvimento do câncer de pele não melanoma. A foto edução aprendida desde a infância e a mudança dos hábitos de vida, podem reduzir a incidência deste câncer, que ainda configura um problema de saúde pública e que necessita de mais investimentos dos órgãos governamentais, como novas políticas públicas voltadas para a conscientização, educação e prevenção.

\section{REFEFÊNCIAS}

AGBAI, Oma N.; et al. Skin cancer and photoprotection in people of color: A review and recommendations for physicians and the public. v. 70, n. 4, pg. 748-762, Apr, 2014. Disponível em: http://www.sciencedirect.com/science/article/pii/S0190962213012966. Acesso em: 15 out 2017.

ARANGO, Ana Cecilia Mesa; MUÑOZ, Sindy Viviana Flórez; SANCLEMENTE, Gloria. Mecanismos de envelhecimento da pele. Iatreia.v.30, n.2, Medellín, Apr/Jun, 2017. Disponível em: http://www.scielo.org.co/scielo.php?script=sci_arttext\&pid=S012107932017000200160\&lang=pt. Acesso em: 18 out 2017.

BALOGH, Tatiana Santana; et al. Proteção à radiação ultravioleta: recursos disponíveis na atualidade em fotoproteção. An. Bras. Dermatol, v.86, n.4, Rio de Janeiro, July/Aug, 2011. Disponível em> http://www.scielo.br/scielo.php?script=sci_arttext\&pid=S0365$05962011000400016 \&$ lang=pt. Acesso em: 10 out 2017.

BARUCCI, Fernanda de Mattos Pereira, et al. Perfil e características anatomopatológicas em 100 pacientes com câncer de pele não melanoma. Rev. Bras. Cir. Cabeça Pescoço, v.44, n3, p. 124-129, Jul/Set. 2015. Disponível em: http://www.sbccp.org.br/wpcontent/uploads/2015/07/Rev-SBCCP-44-3-artogo-02.pdf. Acesso em 10 out 2017.

BEZERRA, Sarita Maria de Fátima Martins de Carvalho; et al. Efeitos da radiação solar crônica prolongada sobre o sistema imunológico de pescadores profissionais em Recife (PE), 
Brasil. An. Bras. Dermatol, v.86, n.2, Rio de Janeiro, Mar/Apr, 2011. DisponAn. Bras. Dermatol. vol.86 no.2 Rio de Janeiro Mar./Apr. 2011. Disponível em: http://www.scielo.br/scielo.php?script=sci_arttext\&pid=S0365$05962011000200004 \&$ lang=pt. Acesso em: 10 out 2017.

BONAMIGO, Renan Rangel; et al. HLA e câncer de pele. An. Bras. Dermatol, v.87, n.1, Rio de Janeiro, Jan/Feb, 2012. Disponível em: http://www.scielo.br/scielo.php?script=sci_arttext\&pid=S0365$05962012000100001 \&$ lang=pt. Acesso em 15 out 2017.

BRITO, Susy Mara Cunha de; MESCHEDE, Marina Smidt Celere; GONÇALVES, Thayná Pimentel; PONTES, Wagner Fernandes. O conhecimento dos mototaxistas sobre a problemática do câncer de pele no município de Santarém, Pará. Revista de Publicação Acadêmica da Pós-Graduação do IESPES. p. 57-69 Disponível em: http://iespes.edu.br/revistaemfoco/index.php/Foco/article/view/56/47. Acesso em 15 out 2017

BURNETT, Mark ; HU, Judy Y.; WANG, Steven Q. Sunscreens: Obtaining adequate Photoprotection. Dermatologic Therapy, v. 25, p. 244-251, 2012.

B. Kutting.; H. Drexler. UV-induced skin cancer at workplace and evidence-based prevention. v. 83, n. 8, p. 843-854, dez, 2010. Disponivel em: https://www.ncbi.nlm.nih.gov/pubmed/20414668. Acesso em: 10 out 2017.

CASTILHO, Ivan Gagliardi; SOUSA, Maria Aparecida Alves; LEITE, Rubens Marcelo Souza. Fotoexposição e fatores de risco para câncer da pele: uma avaliação de hábitos e conhecimentos entre estudantes universitários. An. Bras. Dermatol, v.85, n.2, Rio de Janeiro, Mar/Apr. 2010. http://www.scielo.br/scielo.php?script=sci_arttext\&pid=S0365$05962010000200007 \&$ lang=pt. Acesso em: 18 out 2017.

CARLOS, Francisco. Radiações Ultravioleta e suas implicações na saúde humana no contexto da divulgação científica. São Paulo. Nov. 2009.

CEONI, Francisco Carlos. Radiações Ultravioleta e suas implicações na saúde humana no contexto da divulgação científica. São Paulo. Nov. 2009.

CHINEM, Valquiria Pessoa; MIOT, Hélio Amante. Epidemiologia do carcinoma basocelular. An. Bras. Dermatol, v.86, n.2, Rio de Janeiro, Mar/Apr, 2011. Disponível em: http://www.scielo.br/scielo.php?script=sci_arttext\&pid=S0365-

$05962011000200013 \&$ lang=pt. Acesso em: 20 out 2017. 
FREITAS, José Octávio Gonçalves de; et al. Tratamento cirúrgico dos carcinomas basocelular e espinocelular: experiência dos Serviços de Cirurgia Plástica do Hospital Ipiranga. Rev. Bras. Cir. Plást, v.27, n.4, São Paulo, Oct./Dec, 2012. Disponível em: http://www.scielo.br/scielo.php?script=sci_arttext\&pid=S1983-

$51752012000400009 \&$ lang=pt. Acesso em 20 out 2017.

FERREIRA, Flávia Regina; NASCIMENTO, Luiz Fernando Costa; ROTTA, Osmar . Fatores de risco para câncer da pele não melanoma em Taubaté, SP: um estudo caso-controle. Rev. Assoc. Med. Bras., v.57, n.4 São Paulo, July/Aug, 2011. Disponível em: http://www.scielo.br/scielo.php?script=sci_arttext\&pid=S0104$42302011000400018 \&$ lang=pt. Acesso em 18 out 2017.

GROFF, A.A.(2008): O Tambaqui(Colossoma macropomum) e o Pirarucu(Arapaima gigas) como organismos bio indicadores do efeito genotóxico da radiação ultravioleta( UVA e UVB). Disponível em: http://www.lume.ufrgs.br/bitstream/handle/10183/15487/000678232.pdf?sequence=1. Acesso em: 10 out 2017.

IMANICHI, Danielle; et al. Fatores de risco do câncer de pele não melanoma em idosos no Brasil. Diang. Tratamento, v. 22, n. 1, p. 3-7, 2017.

IBGE - Instituto Brasileiro de Geografia e Estatística. Disponível em: https://www.ibge.gov.br/estatisticas-novoportal/sociais/habitacao/9221-sintese-deindicadores-sociais.html?\&t=downloads. Acesso em: 05 nov 2017.

JUNQUEIRA, Luiz Carlos Uchoa; CARNEIRO, José. Biologia Celular e Molecular. 9 ed. Guanabara Koogan: Rio Janeiro, 2012.

KIM, Young.; YING, Yu. Ultraviolet radiation-induced non-melanoma skin cancer: Regulation of DNA damage repair and inflammation. v. 1, n. 2, p. 188-198, Dez, 2014. Disponível em: http://www.sciencedirect.com/science/article/pii/S2352304214000178. Acesso em: 20 out 2017.

MARGOTTO, Fernanda Serrão; et al. Fotoexposição e fatores de risco para câncer de pele: avaliação de hábitos e conhecimentos da população participante da campanha de prevenção ao câncer de pele em Morro Redondo/RS. Revista da AMRIGS, v. 60, n1, Porto Alegre, jan/mar. 2016 Disponível em: http://www.amrigs.org.br/revista/60-01/07.pdf. Acesso em: 10 out 2017.

NICHOLS, Joi A. , KATIYAR, Santosh K. Skin photoprotection by natural polyphenols: Anti-inflammatory, anti-oxidant and DNA repair mechanisms. Arch Dermatol Res. v. 302, n. $2, \quad$ p. $71, \quad$ mar. 2010. Disponível em: 
https://www.ncbi.nlm.nih.gov/pmc/articles/PMC3498471/?tool=pubmed. Acesso em: 15 out 2017.

OLIVEIRA, Marcia Maria Fernandes de. Radiação Ultravioleta/ Índice Ultravioleta e Câncer de Pele no Brasil: Condições ambientais e vulnerabilidades sociais. Revista Brasileira de Climatologia, ano 9, v. 13, p. 1-14, jul/dez, 2013.

OKUNO, E.; VILELLA, M.A.C. Radiação Ultravioleta: Características e Efeitos. Editora Livraria da Física, São Paulo, 79 p., 2005.

Pele não melanoma. Disponível em: http://www2.inca.gov.br/wps/wcm/connect/tiposdecancer/site/home/pele_nao_melanoma.

Acesso em: 10 out 2017.

PIETRAFESA, José Paulo; BORBA, Odiones de Fátima; MENDES, Carlos Hassel; PEREIRA, Libna Lemos Ignácio; Pereira, Roberto Alves. Redação Científica: orientações e normas. Anápolis: Associação Educativa Evangélica, 2015.

RAMOS, Albenides. Metodologia da Pesquisa Científica: como uma monografia pode abrir o horizonte do conhecimento. V 1, São Paulo: Atlas, 2009.

RIZZATTI, Karoline; SCHNEIDER, Ione Jayce Ceola; D'ORDI, Eleonora. Perfil epidemiológico dos cidadãos de Florianópolis quanto à exposição solar. Epidemiol. Serv. Saúde, v.20, n.4, Brasília, dez, 2011. Disponível em: http://scielo.iec.pa.gov.br/scielo.php?pid=S1679-

$49742011000400005 \&$ script=sci_arttext\&tlng=en. Acesso em 05 out 2017.

ROBBINS, Stanley Leonard; COTRAN, Ramzi S.; KUMAR, Vinay; ABBAS, Abel K.; FAUSTO, Nelson. Patologia: Bases Patológicas das Doenças. $4^{\mathrm{a}}$ tiragem, 7 ed. Rio de Janeiro: Elsevier, 2005.

RODRIGUES, Adrea Bezerra; MARTIN, Leila Gonçalves Rocha; MORAES, Marcia Wanderley de. Oncologia Multiprofissional: patologia, assistências e gerenciamento. Manole: Barueri - São Paulo, 2016.

SANTOS, João Correia dos. Radiação ultravioleta: Estudo dos índices de radiação, conhecimento e prática de prevenção a exposição na região Ilheus/Itabuna - Bahia. 2010. Disponível em: http://www.biblioteca.uesc.br/biblioteca/bdtd/733767599d.pdf. Acesso em: 10 out 2017. 
SILVA A. C. Silva; CRISTINA, Ângela. Meio ambiente e saúde humana: variabilidade temporal da radiação ultravioleta e epidemiologia do câncer de pele na região Oeste do Estado de São Paulo - Presidente Prudente: Dissertação (mestrado) - Universidade Estadual Paulista, Faculdade de Ciências e Tecnologia, 2007.

SILVA. José Alencar Gomes da Silva. Estimativa 2016: incidência de câncer no Brasil . Instituto Nacional de Câncer. Rio de Janeiro: INCA, 2015. Disponível em: http://www.inca.gov.br/estimativa/2016/estimativa-2016-v11.pdf. Acesso em: 20 out 2017.

SILVA. Gabriela Dias da; OGAWA, Melina Mayumi; SOUZA, Priscila Castro de. Os efeitos da exposição à radiação ultravioleta ambiental. 2017. Disponível: http://www.ebah.com.br/content/ABAAAeiqAAJ/ultravioleta. Acesso em 05 out 2017.

SCHALKA, Sérgio; et al. Brazilian Consensus on Photoprotection. An. Bras. Dermatol. v.89, n.6, supl.1 Rio de Janeiro, Nov/Dez. 2014. Disponível em: https://www.ncbi.nlm.nih.gov/pmc/articles/PMC2813915/. Acesso em: 18 out 2017.

SGARBI, Flávia Celina; CARMO, Eliane Dias do; ROSA, Luiz Eduardo Blumer. Radiação Ultravioleta e Carcinogênese. Rev. Ciênc. Méd., v.4, n.6, p. 245-250, jul/dez. 2007.

UOUNG, Antony R. et al. Ultraviolet radiation and the skin: Photobiology and sunscreen photoprotection. AM ACAD DERMATOL. 2016.

V. W. J. H. Kirchhoff 1, E. Echer 2, N. P. Leme 3 \& A. A. Silva. A variação sazonal da radiação ultravioleta solar biologicamente ativa. Brazilian Journal of Geophysics, Vol. 18, n.1, 2000. Disponível em: http://www.scielo.br/scielo.php?script=sci_arttext\&pid=S0365$05962014000700001 \& \operatorname{lng}=\mathrm{en} \& \ln g=\mathrm{en}$. Acesso em: 10 out 2017.

VAZ, Marta Regina Cezar, et al. Cáncer de piel en trabajadores rurales: conocimiento e intervención de enfermeira. Rev. esc. enferm. USP, v.49, n.4, São Paulo, Jul/Aug, 2015. Disponível em: http://www.scielo.br/scielo.php?script=sci_arttext\&pid=S008062342015000400564\&lang=pt\#t1. Acesso em: 20 out 2017.

VIDEIRA, Inês Ferreira dos Santos; MOURA, Daniel Filipe Lima; MAGINA, Sofia. Mecanismos reguladores da melanogênese. An. Bras. Dermato, v.88, n.1, Rio de Janeiro, Jan./Feb, 2013. http://www.scielo.br/scielo.php?script=sci_arttext\&pid=S036505962013000100076\&lang=pt. Acesso em: 10 nov 2017. 
FIGURA E TABELAS

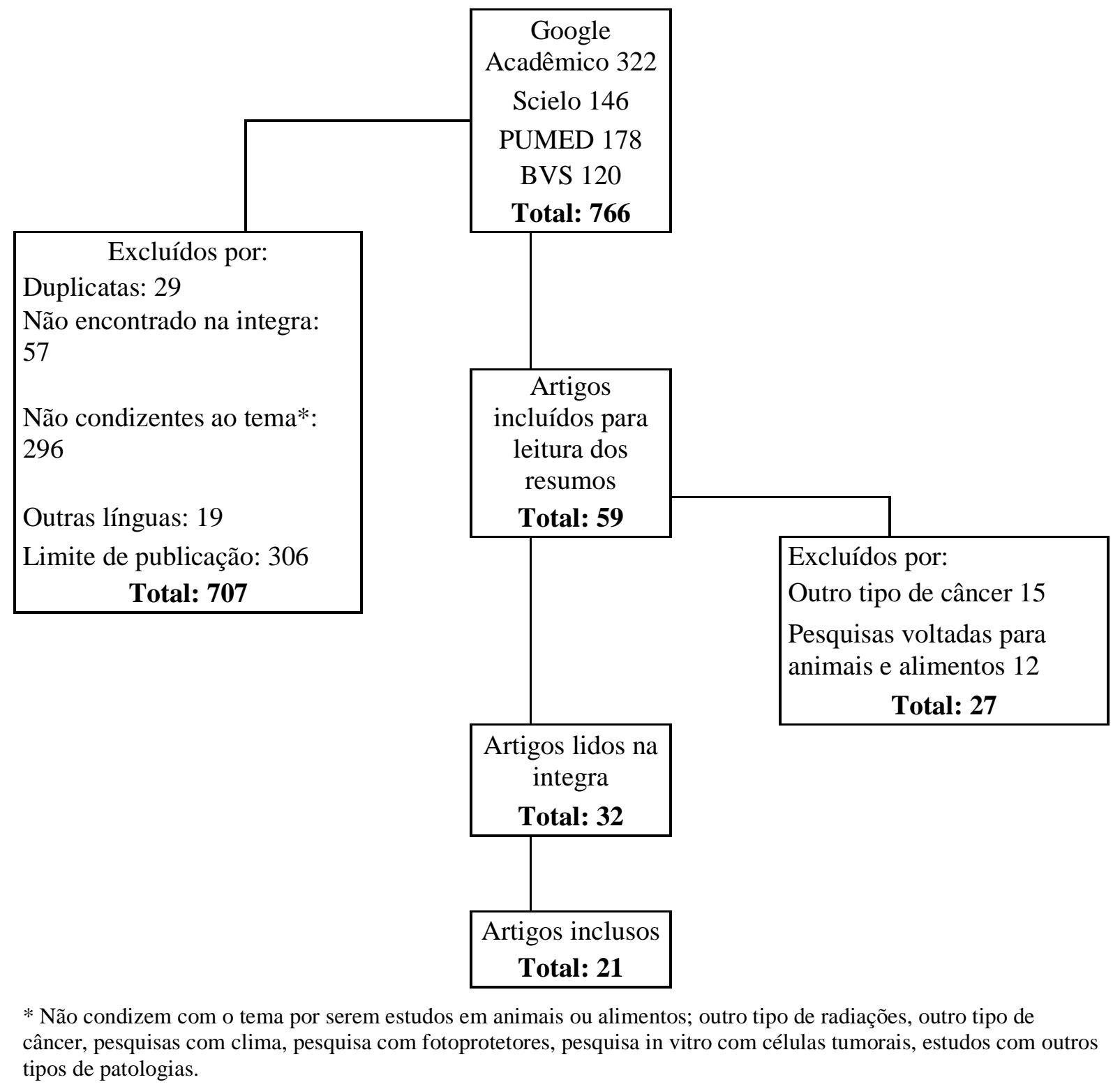

Figura 1: Fluxograma de busca e seleção dos artigos 
Tabela 1. Estimativa geral de novos casos de câncer de pele não melanoma por sexo, capitais, estados e regiões do Brasil (2016).

Estimativa geral de novos casos de câncer de pele não melanoma por sexo nos Estados e Capitais do Brasil em 2016.

\begin{tabular}{l|c|c|c|c|c|c|c}
\hline \multicolumn{3}{c|}{ HOMENS } & \multicolumn{4}{c}{ MULHERES } \\
\hline \multicolumn{2}{c|}{ Estados } & \multicolumn{2}{c|}{ Capitais } & \multicolumn{2}{c|}{ Estados } & \multicolumn{2}{c}{ Capitais } \\
\hline Casos & Taxa Bruta & Casos & Taxa Bruta & Casos & Taxa Bruta & Casos & Taxa Bruta \\
80.850 & 81,66 & 17.340 & 80,90 & 94.910 & 91,98 & 21.750 & 91,65 \\
& & & & & & & \\
\hline
\end{tabular}

Estimativa geral de novos casos de câncer de pele não melanoma por sexo nas regiões do Brasil em 2016.

\begin{tabular}{|c|c|c|c|c|c|}
\hline REGIÕES & \multicolumn{2}{|c|}{ HOMENS } & \multicolumn{2}{|c|}{ MULHERES } & TOTAL \\
\hline NORTE & \multicolumn{2}{|c|}{2.410} & \multicolumn{2}{|c|}{1.890} & 4.300 \\
\hline NORDESTE & \multicolumn{2}{|c|}{11.720} & \multicolumn{2}{|c|}{12.750} & 24.470 \\
\hline CENTRO-OESTE & \multicolumn{2}{|c|}{8.560} & \multicolumn{2}{|r|}{7.790} & 16.350 \\
\hline SUL & \multicolumn{2}{|c|}{19.730} & \multicolumn{2}{|c|}{13.820} & 33.550 \\
\hline SUDESTE & \multicolumn{2}{|c|}{38.430} & \multicolumn{2}{|c|}{58.660} & 97.090 \\
\hline \multirow{2}{*}{$\begin{array}{l}\text { GOIÁS E } \\
\text { GOIÂNIA }\end{array}$} & $\begin{array}{l}\text { Casos } \\
\text { Estado }\end{array}$ & $\begin{array}{c}\text { Casos } \\
\text { Capital }\end{array}$ & $\begin{array}{l}\text { Casos } \\
\text { Estado }\end{array}$ & Casos Capital & TOTAL \\
\hline & 3.140 & 910 & 3.060 & 640 & 7.750 \\
\hline
\end{tabular}

* Estimativa por 100.000 habitantes para o ano de 2016 (Adaptada, INCA, 2015). 
Tabela 2 - Distribuição percentual da população residente, por cor ou raça, com indicação do coeficiente de variação (CV), 2015.

\begin{tabular}{|c|c|c|c|c|}
\hline \multirow{3}{*}{$\begin{array}{c}\text { Grandes Regiões, Unidades da Federação } \\
\text { e Regiões Metropolitanas. }\end{array}$} & \multicolumn{4}{|c|}{$\begin{array}{l}\text { Distribuição percentual da população } \\
\text { residente, por cor ou raça }(\%) \text {. }\end{array}$} \\
\hline & \multicolumn{2}{|c|}{ Branca } & \multicolumn{2}{|c|}{ Preta ou Parda } \\
\hline & Percentual & $\mathrm{CV}(\%)$ & Percentual & $\mathrm{CV}(\%)$ \\
\hline Brasil & 45,2 & $\mathbf{0 , 5}$ & 53,9 & $\mathbf{0 , 4}$ \\
\hline Norte & 21,2 & $\mathbf{1 , 8}$ & 77,3 & $\mathbf{0 , 7}$ \\
\hline Rondônia & 31,4 & 3,0 & 68,0 & $\overline{1,4}$ \\
\hline Acre & 21,4 & 5,1 & 74,3 & 4,8 \\
\hline Amazonas & 19,9 & 5,1 & 77,5 & 1,4 \\
\hline Roraima & 20,7 & 7,0 & 76,3 & 2,3 \\
\hline Pará & 19,0 & 2,7 & 79,7 & 1,0 \\
\hline Região Metropolitana de Belém & 22,5 & 3,1 & 76,8 & 0,9 \\
\hline Amapá & 23,1 & 5,9 & 76,4 & 1,9 \\
\hline Tocantins & 23,3 & 5,9 & 76,4 & 1,8 \\
\hline Nordeste & 26,4 & 1,2 & 73,0 & $\overline{0,4}$ \\
\hline Maranhão & 19,7 & 5,5 & 79,7 & 1,5 \\
\hline Piauí & 21,6 & 6,0 & 78,3 & 1,6 \\
\hline Ceará & 28,4 & 2,9 & 71,1 & 1,1 \\
\hline Região Metropolitana de Fortaleza & 28,1 & 2,7 & 71,3 & 1,1 \\
\hline Rio Grande do Norte & 40,5 & 4,2 & 59,5 & 2,8 \\
\hline Paraíba & 36,3 & 3,1 & 62,8 & 1,9 \\
\hline Pernambuco & 32,5 & 2,4 & 66,8 & 1,0 \\
\hline Região Metropolitana de Recife & 30,2 & 2,6 & 69,3 & 1,1 \\
\hline Alagoas & 27,0 & 4,4 & 72,6 & 1,5 \\
\hline Sergipe & 25,4 & 4,5 & 74,1 & 1,6 \\
\hline Bahia & 19,7 & 2,8 & 79,5 & 0,8 \\
\hline Região Metropolitana de Salvador & 13,9 & 5,5 & 85,7 & 0,9 \\
\hline Sudeste & 52,9 & $\mathbf{0 , 8}$ & 46,2 & $\mathbf{1 , 0}$ \\
\hline Minas Gerais & 42,2 & 1,9 & 57,4 & 1,5 \\
\hline Região Metropolitana de Belo Horizonte & 37,4 & 2,7 & 62,3 & 1,6 \\
\hline Espírito Santo & 41,8 & 5,1 & 57,8 & 3,7 \\
\hline Rio de Janeiro & 45,5 & 1,7 & 54,1 & 1,4 \\
\hline Região Metropolitana do Rio de Janeiro & 44,3 & 2,1 & 55,2 & 1,7 \\
\hline São Paulo & 61,6 & 1,1 & 37,0 & 1,9 \\
\hline Região Metropolitana de São Paulo & 58,2 & 1,6 & 39,9 & 2,5 \\
\hline Sul & 76,7 & $\mathbf{0 , 7}$ & 22,5 & 2,3 \\
\hline Paraná & 68,1 & 1,4 & 30,7 & 3,2 \\
\hline Região Metropolitana de Curitiba & 77,2 & 1,3 & 21,5 & 4,7 \\
\hline Santa Catarina & 85,3 & 1,2 & 14,4 & 7,0 \\
\hline Rio Grande do Sul & 80,1 & 1,0 & 19,4 & 3,8 \\
\hline Região Metropolitana de Porto Alegre & 81,1 & 0,9 & 18,5 & 3,8 \\
\hline Centro-Oeste & 39,4 & $\mathbf{1 , 5}$ & $\mathbf{5 9 , 9}$ & $\mathbf{1 , 0}$ \\
\hline Mato Grosso do Sul & 45,2 & 2,9 & 53,5 & 2,5 \\
\hline Mato Grosso & 33,2 & 4,7 & 66,2 & 2,4 \\
\hline Goiás & 39,1 & 2,0 & 60,2 & 1,3 \\
\hline Distrito Federal & 41,7 & 2,8 & 57,3 & 2,0 \\
\hline
\end{tabular}


Fonte: IBGE. Pesquisa Nacional por Amostra de Domicílios 2015 (Adaptada, IBGE, 2016). 
APÊNDICE

APÊNDICE 1. Artigos selecionados por protocolo de busca para Radiação UV e Câncer de Pele Não Melanoma (material suplementar).

\begin{tabular}{|c|c|c|c|c|c|}
\hline AUTOR & REVISTA & $\begin{array}{l}\mathrm{V}^{\circ} / \mathbf{N}^{\circ} / \\
\text { ANO }\end{array}$ & $\begin{array}{l}\text { TIPO DE } \\
\text { ESTUDO }\end{array}$ & OBJETIVO PRINCIPAL & PRINCIPAIS RESULTADOS \\
\hline $\begin{array}{l}\text { Schalka S, } \\
\text { Steiner D, } \\
\text { Ravelli FN, } \\
\text { Steiner T, } \\
\text { Terena AC, } \\
\text { Marçon CR, et } \\
\text { al. }\end{array}$ & $\begin{array}{l}\text { Anais } \\
\text { Brasileiros de } \\
\text { Dermatologia. }\end{array}$ & $\begin{array}{l}\text { Volume } 89, \\
\text { número } 6, \\
\text { ano } 2014 .\end{array}$ & $\begin{array}{l}\text { Descritivo - } \\
\text { Revisão } \\
\text { bibliográfica. }\end{array}$ & $\begin{array}{l}\text { Prevenir os danos causados } \\
\text { pela radiação solar através da } \\
\text { fotoproteção }\end{array}$ & $\begin{array}{l}\text { O risco de danos causados pela energia solar e } \\
\text { câncer de pele com exposição excessiva à } \\
\text { radiação UV, bem como a suplementação oral de } \\
\text { vitamina D disponível, estabelecem diretrizes } \\
\text { para a definição de níveis ideais e seguros de } \\
\text { exposição ao sol. }\end{array}$ \\
\hline $\begin{array}{l}\text { Nichols JA, } \\
\text { Katiyar SK. }\end{array}$ & $\begin{array}{l}\text { Archives of } \\
\text { Dermatological } \\
\text { Research. }\end{array}$ & $\begin{array}{l}\text { Volume } \\
302, \\
\text { número } 2, \\
\text { ano } 2010 .\end{array}$ & $\begin{array}{l}\text { Analítico }- \\
\text { Ensaio } \\
\text { clínico }\end{array}$ & $\begin{array}{l}\text { O uso de polifenóis para } \\
\text { complementar a proteção dos } \\
\text { protetores solares e proteger a } \\
\text { pele dos efeitos adversos da } \\
\text { radiação UV, incluindo o } \\
\text { risco de câncer de pele. }\end{array}$ & $\begin{array}{l}\text { Evidência epidemiológica } \mathrm{e} \text { estudos de } \\
\text { laboratório utilizando sistemas in vitro e in vivo, } \\
\text { sugere-se que o consumo de rotina ou o } \\
\text { tratamento tópico desses polifenóis pode } \\
\text { fornecer proteção eficiente contra os efeitos } \\
\text { nocivos da radiação ultravioleta solar em seres } \\
\text { humanos. }\end{array}$ \\
\hline $\begin{array}{l}\text { Fartasch M, } \\
\text { Diepgen TL, } \\
\text { Schmitt J, } \\
\text { Drexler H. }\end{array}$ & $\begin{array}{l}\text { Deutsches } \\
\text { Arzteblatt } \\
\text { International. }\end{array}$ & $\begin{array}{l}\text { Volume } \\
\text { 109, número } \\
43 \text {, ano } \\
2012 .\end{array}$ & $\begin{array}{l}\text { Descritivo - } \\
\text { Revisão } \\
\text { bibliográfica . }\end{array}$ & $\begin{array}{l}\text { Demonstrar que o câncer de } \\
\text { pele não melanoma é o tipo } \\
\text { mais comum de câncer em } \\
\text { áreas do mundo com uma } \\
\text { população de pele clara. A } \\
\text { exposição ocupacional à } \\
\text { radiação UV é alta em muitas } \\
\text { ocupações ao ar livre e que } \\
\text { pessoas que trabalham com } \\
\text { tais ocupações são mais } \\
\text { propensas a contrair o câncer. }\end{array}$ & $\begin{array}{l}\text { As meta-análises documentaram um risco maior } \\
\text { de carcinoma de células escamosas da pele entre } \\
\text { pessoas que trabalham no exterior (odds ratio } \\
\text { [OR] } 1,77 \text {, intervalo de confiança de } 95 \% \text { [CI] } \\
1,40-2,22, \mathrm{p}<0,001 \text { ). E um risco elevado de } \\
\text { carcinoma basocelular (OR } 1,43 \text {, IC } 95 \% 1,23 \text { - } \\
1,66, p=0,0001 \text {. }\end{array}$ \\
\hline
\end{tabular}




\begin{tabular}{|c|c|c|c|c|c|}
\hline AUTOR & REVISTA & $\begin{array}{l}\mathrm{V}^{\circ} / \mathbf{N}^{\circ} / \\
\text { ANO }\end{array}$ & $\begin{array}{l}\text { TIPO DE } \\
\text { ESTUDO }\end{array}$ & OBJETIVO PRINCIPAL & PRINCIPAIS RESULTADOS \\
\hline $\begin{array}{l}\text { Margotto FS, } \\
\text { Silva HP, } \\
\text { Meireles RS, } \\
\text { Neugebauer } \\
\text { MGFP, Abrahão } \\
\text { GF, Rauber JL. }\end{array}$ & $\begin{array}{l}\text { Revista } \\
\text { AMRIGS - } \\
\text { Associação } \\
\text { Médica do Rio } \\
\text { Grande do Sul. }\end{array}$ & $\begin{array}{l}\text { Volume } 60, \\
\text { número } 1, \\
\text { ano } 2016 .\end{array}$ & $\begin{array}{l}\text { Descritivo } \\
\text { Transversal. }\end{array}$ & $\begin{array}{l}\text { Relacionar o uso de protetor } \\
\text { solar diário ou eventual com } \\
\text { conhecimento da relação } \\
\text { causal entre o sol e o câncer } \\
\text { de pele, tal como a presença } \\
\text { ou ausência de lesão de pele } \\
\text { suspeita de neoplasia maligna } \\
\text { em relação ao conhecimento } \\
\text { sobre a relação supracitada. }\end{array}$ & $\begin{array}{l}\text { Uso diário de fotoprotetor foi mais frequente } \\
\text { entre as mulheres }(21,49 \%) \text { e a prevalência de } \\
\text { lesão suspeita de malignidade nesse grupo foi } \\
\text { nula, enquanto que } 20,55 \% \text { dos homens } \\
\text { referiram nunca se proteger, e dentre eles o } \\
\text { predomínio de lesões suspeitas foi de } 7,47 \text {. }\end{array}$ \\
\hline $\begin{array}{l}\text { Mesa-Arango } \\
\text { AC, Flórez- } \\
\text { Muñoz SV, } \\
\text { Sanclemente G. }\end{array}$ & Iatreia. & $\begin{array}{l}\text { Volume } 30, \\
\text { número 2, } \\
\text { ano } 2017 .\end{array}$ & $\begin{array}{l}\text { Descritivo - } \\
\text { Revisão } \\
\text { bibliográfica . }\end{array}$ & $\begin{array}{l}\text { Utilizar novas e atuais } \\
\text { perspectivas para prevenção e } \\
\text { opções de tratamento } \\
\text { extraídas de produtos naturais } \\
\text { nos mecanismos intrínsecos e } \\
\text { extrínsecos do } \\
\text { envelhecimento da pele. }\end{array}$ & $\begin{array}{l}\text { Tentativas crescentes estão sendo feitas para } \\
\text { atrasar o envelhecimento da pele através da } \\
\text { ingestão ou aplicação de produtos naturais ou } \\
\text { pela formulação de novos protetores solares } \\
\text { naturais com maior capacidade de proteção } \\
\text { contra radiação. A biodiversidade vegetal nos } \\
\text { países latino-americanos, e particularmente na } \\
\text { Colômbia, são fontes importantes de potenciais } \\
\text { candidatos para uso tópico. }\end{array}$ \\
\hline $\begin{array}{l}\text { Cezar-Vaz MR, } \\
\text { Bonow CA, } \\
\text { Piexak } \\
\text { DR, Kowalczyk } \\
\text { S, Vaz DR, } \\
\text { Borges AM. }\end{array}$ & $\begin{array}{l}\text { Revista da } \\
\text { Escola de } \\
\text { Enfermagem da } \\
\text { USP. }\end{array}$ & $\begin{array}{l}\text { Volume } 49, \\
\text { número } 4, \\
\text { ano } 2015 .\end{array}$ & $\begin{array}{l}\text { Analítico } \\
\text { observacional }\end{array}$ & $\begin{array}{l}\text { Identificar a exposição dos } \\
\text { trabalhadores rurais à } \\
\text { radiação ultravioleta e aos } \\
\text { pesticidas do sol; para } \\
\text { identificar casos anteriores de } \\
\text { câncer de pele; e implementar } \\
\text { ações clínicas comunicativas } \\
\text { de enfermagem entre } \\
\text { trabalhadores rurais com } \\
\text { diagnóstico prévio de câncer }\end{array}$ & $\begin{array}{l}\text { Um total de } 123(97,7 \%) \text { trabalhadores foram } \\
\text { identificados sob condições de exposição à } \\
\text { radiação ultravioleta e aos pesticidas; sete } \\
(5,4 \%) \text { foram identificados com um diagnóstico } \\
\text { prévio de câncer de pele; quatro }(57,1 \%) \\
\text { apresentaram possíveis lesões de câncer de pele. }\end{array}$ \\
\hline
\end{tabular}

REFACER v. 6, n. 2, 2017. ISSN - 2317-1367 


\begin{tabular}{|c|c|c|c|c|c|}
\hline & & & & de pele. & \\
\hline AUTOR & REVISTA & $\begin{array}{l}\mathrm{V}^{\circ} / \mathbf{N}^{\circ} / \\
\text { ANO }\end{array}$ & $\begin{array}{l}\text { TIPO DE } \\
\text { ESTUDO }\end{array}$ & OBJETIVO PRINCIPAL & PRINCIPAIS RESULTADOS \\
\hline $\begin{array}{l}\text { Videira IFS, } \\
\text { Moura DFL, } \\
\text { Magina S. }\end{array}$ & $\begin{array}{l}\text { Anais } \\
\text { Brasileiros de } \\
\text { Dermatologia. }\end{array}$ & $\begin{array}{l}\text { Volume } 88, \\
\text { número } 01, \\
\text { ano } 2013 .\end{array}$ & $\begin{array}{l}\text { Descritivo - } \\
\text { Revisão } \\
\text { bibliográfica }\end{array}$ & $\begin{array}{l}\text { A identificar e compreender o } \\
\text { mecanismo de melanogênese } \\
\text { para facilitar a compreensão } \\
\text { da patogênese dos distúrbios } \\
\text { de pigmentação e o } \\
\text { desenvolvimento de } \\
\text { potenciais opções } \\
\text { terapêuticas. }\end{array}$ & $\begin{array}{l}\text { Diferentes tipos de interação entre melanócitos } \\
\text { e outras células (incluindo queratinócitos) e } \\
\text { sistemas (SNC, imune, inflamatório, endócrino e } \\
\text { endocanabinoide), aumentando o papel da pele } \\
\text { como órgão neuroendócrino. Foram observados } \\
\text { que o UVR é um fator extrínseco importante e a- } \\
\text { MSH um importante fator intrínseco. }\end{array}$ \\
\hline $\begin{array}{l}\text { Balogh TS, } \\
\text { Velasco MVR, } \\
\text { Pedriali CA, } \\
\text { Kaneko TM, } \\
\text { Baby AR. }\end{array}$ & $\begin{array}{l}\text { Anais } \\
\text { Brasileiros de } \\
\text { Dermatologia. }\end{array}$ & $\begin{array}{l}\text { Volume } 86, \\
\text { número } 4, \\
\text { ano } 2011,\end{array}$ & $\begin{array}{l}\text { Descritivo - } \\
\text { Revisão } \\
\text { bibliográfica . }\end{array}$ & $\begin{array}{l}\text { Apresentar e discutir as } \\
\text { principais formas de } \\
\text { fotoproteção, incluindo os } \\
\text { protetores solares com filtros } \\
\text { inorgânicos e orgânicos, a } \\
\text { avaliação da eficácia dos } \\
\text { mesmos e atualizações } \\
\text { envolvendo o tema. }\end{array}$ & $\begin{array}{l}\text { A fotoproteção é incontestável, na ação } \\
\text { profilática e terapêutica contra o envelhecimento } \\
\text { precoce, e na diminuição da incidência de câncer } \\
\text { de pele. A eficácia fotoprotetora pode ser } \\
\text { determinada por metodologias in vitro e in vivo. }\end{array}$ \\
\hline $\begin{array}{l}\text { Chinem VP, } \\
\text { Miot HÁ. }\end{array}$ & $\begin{array}{l}\text { Anais } \\
\text { Brasileiros de } \\
\text { Dermatologia. }\end{array}$ & $\begin{array}{l}\text { Volume } 86, \\
\text { número 2, } \\
\text { ano 2011, }\end{array}$ & $\begin{array}{l}\text { Descritivo - } \\
\text { Revisão } \\
\text { bibliográfica }\end{array}$ & $\begin{array}{l}\text { Prevenir o carcinoma } \\
\text { basocelular baseando-se no } \\
\text { conhecimento de fatores de } \\
\text { risco, no diagnóstico e } \\
\text { tratamento precoces e na } \\
\text { adoção de medidas } \\
\text { específicas, principalmente, } \\
\text { nas populações susceptíveis. }\end{array}$ & $\begin{array}{l}\text { A diagnóstica precoce leva a intervenções } \\
\text { cirúrgicas menos sequelantes, os maiores } \\
\text { acessos ao serviço de saúde e sensibilização da } \\
\text { população pelas campanhas educativas fizeram } \\
\text { que o prognóstico do carcinoma basocelular } \\
\text { parecesse ter melhorado nas últimas décadas em } \\
\text { todos os países. }\end{array}$ \\
\hline $\begin{array}{l}\text { Bezerra } \\
\text { SMFMC, Sotto } \\
\text { MN, Orii NM, } \\
\text { Alves C, Duarte }\end{array}$ & $\begin{array}{l}\text { Anais } \\
\text { Brasileiros de } \\
\text { Dermatologia. }\end{array}$ & $\begin{array}{l}\text { Volume } 86, \\
\text { número 2, } \\
\text { ano 2011, }\end{array}$ & $\begin{array}{l}\text { Prospectivo } \\
\text { observacional. }\end{array}$ & $\begin{array}{l}\text { Avaliar efeitos clínicos, } \\
\text { histológicos e imunológicos } \\
\text { da exposição crônica e } \\
\text { prolongada à radiação }\end{array}$ & $\begin{array}{l}\text { Houve diferenças entre os grupos exposto e } \\
\text { protegido em elastose }(\mathrm{p}=0,03) \text {, ectasia de } \\
\text { vasos dérmicos }(\mathrm{p}=0,012) \text { e número de células } \\
\text { nas camadas epidérmicas entre os cones }(\mathrm{p}=\end{array}$ \\
\hline
\end{tabular}

REFACER v. 6, n. 2, 2017. ISSN - 2317-1367 


\begin{tabular}{|c|c|c|c|c|c|}
\hline AJS & & & & ultravioleta em pescadores. & $0,029)$. \\
\hline AUTOR & REVISTA & $\begin{array}{l}\mathrm{V}^{\circ} / \mathrm{N}^{\circ} / \\
\text { ANO }\end{array}$ & $\begin{array}{l}\text { TIPO DE } \\
\text { ESTUDO }\end{array}$ & OBJETIVO PRINCIPAL & PRINCIPAIS RESULTADOS \\
\hline $\begin{array}{l}\text { Castilho IG, } \\
\text { Sousa MAA, } \\
\text { Leite RMS. }\end{array}$ & $\begin{array}{l}\text { Anais } \\
\text { Brasileiros de } \\
\text { Dermatologia. }\end{array}$ & $\begin{array}{l}\text { Volume } 85, \\
\text { número 2, } \\
\text { ano, } 2010 .\end{array}$ & $\begin{array}{l}\text { Analítico, } \\
\text { observacional. }\end{array}$ & $\begin{array}{l}\text { Avaliar hábitos de } \\
\text { fotoexposição e fotoproteção, } \\
\text { bem como conhecimento de } \\
\text { fatores de risco para câncer } \\
\text { da pele, tendo por fim } \\
\text { delinear os padrões de } \\
\text { comportamento dos jovens } \\
\text { perante os efeitos solares. }\end{array}$ & $\begin{array}{l}\text { O uso diário de fotoprotetor foi } \\
\text { significativamente maior entre as mulheres. A } \\
\text { prática de bronzeamento artificial foi baixa }(3,5) \text {. } \\
\text { O uso de filtro solar com fator de proteção maior } \\
\text { do que } 15 \text { ou igual a } 15 \text { foi referido por } 278 \\
\text { estudantes. De modo geral, mais de } 90 \% \text { dos } \\
\text { estudantes acreditam na associação entre } \\
\text { radiação ultravioleta e câncer da pele. Apesar } \\
\text { disso, apenas } 43,5 \% \text { acreditam na genética como } \\
\text { fator de risco. Entre os que rejeitam a hipótese } \\
\text { do fator de risco genético para carcinogênese } \\
\text { cutânea, } 86,2 \% \text { são acadêmicos das Ciências } \\
\text { Humanas. }\end{array}$ \\
\hline $\begin{array}{l}\text { Brito SMC, } \\
\text { Meschede MSC, } \\
\text { Gonçalves TP, } \\
\text { Pontes WF. }\end{array}$ & Revista em Foco & $\begin{array}{l}\text { Volume } 2, \\
\text { número } 24, \\
\text { ano } 2015 .\end{array}$ & $\begin{array}{l}\text { Analítico } \\
\text { observacional }\end{array}$ & $\begin{array}{l}\text { Avaliar o conhecimento dos } \\
\text { mototaxistas da cidade de } \\
\text { Santarém em relação à } \\
\text { problemática do câncer de } \\
\text { pele. }\end{array}$ & $\begin{array}{l}\text { Em relação aos danos da exposição solar a } \\
\text { saúde } 64 \% \text { dos entrevistados demonstrou } \\
\text { conhecimento, entretanto, } 36 \% \text { desconheciam as } \\
\text { reais consequências da exposição solar a saúde. } \\
\text { Dos entrevistados, } 64 \% \text { relataram usar } \\
\text { vestimentas adequadas e o protetor solar diário, } \\
\text { e } 76 \% \text { não o realizam e nunca ouviram falar } \\
\text { sobre o exame clínico da pele. }\end{array}$ \\
\hline
\end{tabular}




\begin{tabular}{|c|c|c|c|c|c|}
\hline $\begin{array}{l}\text { Barucci FMP, } \\
\text { Vetorasso GH, } \\
\text { Cardoso CA, } \\
\text { Priante AVM, } \\
\text { Martins MR. }\end{array}$ & $\begin{array}{l}\text { SBCCP - } \\
\text { Sociedade } \\
\text { Brasileira de } \\
\text { Cirurgia de } \\
\text { Cabeça Pescoço. }\end{array}$ & $\begin{array}{l}\text { Volume } 44, \\
\text { número 3, } \\
\text { ano } 2015 .\end{array}$ & $\begin{array}{l}\text { Retrospectivo } \\
\text { observacional }\end{array}$ & $\begin{array}{l}\text { Avaliar o perfil dos pacientes } \\
\text { e as características } \\
\text { anatomopatológicas dos } \\
\text { CPNM tratados no HRVP. }\end{array}$ & $\begin{array}{l}\text { A idade média foi } 71,6 \text { anos, } 60 \% \text { eram homens, } \\
\text { todos da raça branca. O tipo histológico } \\
\text { predominante foi o carcinoma basocelular } \\
\text { (CBC) }(70 \%) \text {. O local mais acometido pelo CBC } \\
\text { foi o nariz }(40 \%) \text { e pelo carcinoma espinocelular } \\
\text { (CEC), o couro cabeludo }(25,6 \%) \text {. Vinte e três } \\
(17,6 \%) \text { apresentaram invasão perineural. }\end{array}$ \\
\hline AUTOR & REVISTA & $\begin{array}{l}\mathrm{V}^{\circ} / \mathbf{N}^{\circ} / \\
\text { ANO }\end{array}$ & $\begin{array}{l}\text { TIPO DE } \\
\text { ESTUDO }\end{array}$ & OBJETIVO PRINCIPAL & PRINCIPAIS RESULTADOS \\
\hline $\begin{array}{l}\text { Broetto J, } \\
\text { Freitas JOG, } \\
\text { Sperli AE, Soh } \\
\text { SW, Richter } \\
\text { CA, Toni RA. }\end{array}$ & $\begin{array}{l}\text { Revista } \\
\text { Brasileira de } \\
\text { Cirurgia } \\
\text { Plástica. }\end{array}$ & $\begin{array}{l}\text { Volume } 27, \\
\text { número } 4, \\
\text { ano } 2012 .\end{array}$ & $\begin{array}{l}\text { Analítico } \\
\text { observacional. }\end{array}$ & $\begin{array}{l}\text { Analisar os casos de câncer } \\
\text { de pele não melanoma } \\
\text { operados, entre os anos de } \\
2005 \text { e 2010, no Serviço de } \\
\text { Cirurgia Plástica do Hospital } \\
\text { Ipiranga. }\end{array}$ & $\begin{array}{l}\text { De } 145 \text { pacientes, } 15,9 \% \text { apresentavam lesões } \\
\text { múltiplas, totalizando } 168 \text { tumores. Houve } \\
\text { predomínio de CBC, correspondendo a } 87,6 \% \\
\text { dos casos, seguido de CEC, com } 26,2 \% \text {. Os } \\
\text { CBCs sólidos ou nodulares predominaram, com } \\
44,1 \% \text {, e os CECs representaram } 42,1 \% \text { dos } \\
\text { CECs. Dos pacientes, } 80,7 \% \text { possuíam lesão em } \\
\text { face e } 12,4 \% \text {, em membros superiores. A média } \\
\text { de idade dos pacientes foi de } 69,5 \text {. A raça branca } \\
\text { foi mais frequente e o tabagismo foi o principal } \\
\text { fator de risco, presente em } 79,3 \% \text { dos casos. }\end{array}$ \\
\hline
\end{tabular}




\begin{tabular}{|c|c|c|c|c|c|}
\hline $\begin{array}{l}\text { Bonamigo RR, } \\
\text { Carvalho AVE, } \\
\text { Sebastiani VRZ, } \\
\text { Silva CM, Pinto } \\
\text { ACZ. }\end{array}$ & $\begin{array}{l}\text { Anais } \\
\text { Brasileiros de } \\
\text { Dermatologia. }\end{array}$ & $\begin{array}{l}\text { Volume } 87, \\
\text { número 1, } \\
\text { ano } 2012 .\end{array}$ & $\begin{array}{l}\text { Descritivo } \\
\text { Revisão } \\
\text { bibliográfica }\end{array}$ & $\begin{array}{l}\text { Compreender a patogênese e } \\
\text { os fatores genéticos } \\
\text { envolvidos das neoplasias } \\
\text { comuns - os cânceres da pele } \\
\text { melanoma e não melanoma, } \\
\text { pois se constata um aumento } \\
\text { da incidência nas últimas } \\
\text { décadas, se tornando } \\
\text { importante problema de } \\
\text { saúde pública. }\end{array}$ & $\begin{array}{l}\text { Alterações estruturais e funcionais no HLA, } \\
\text { perda de expressão de antígenos tumorais, falta } \\
\text { de moléculas co-estimuladoras e produção de } \\
\text { citocinas imunossupressoras são alguns dos } \\
\text { mecanismos possíveis que causam células } \\
\text { tumorais para escapar da vigilância imunológica. } \\
\text { Antígenos Cw3 e DR1 aumentam a chance de os } \\
\text { pacientes não transplantados desenvolverem } \\
\text { NMSC múltiplo, enquanto que o antígeno B-17 } \\
\text { ofereceu a esses indivíduos alguma proteção. }\end{array}$ \\
\hline $\begin{array}{l}\text { Ferreira FG, } \\
\text { Nascimento } \\
\text { FLC, Rotta O. }\end{array}$ & $\begin{array}{l}\text { Revista da } \\
\text { Associação } \\
\text { Médica } \\
\text { Brasileira. }\end{array}$ & $\begin{array}{l}\text { Volume } 57, \\
\text { número } 4, \\
\text { ano } 2011 .\end{array}$ & $\begin{array}{l}\text { Analítico, } \\
\text { observacional, } \\
\text { caso-controle. }\end{array}$ & $\begin{array}{l}\text { Identificar fatores associados } \\
\text { ao câncer da pele não } \\
\text { melanoma em Taubaté-SP. }\end{array}$ & $\begin{array}{l}\text { Foram } 132 \text { casos e } 132 \text { controles. Compuseram } \\
\text { o modelo final: fototipo com OR = 3,14 (IC 95\% } \\
1,79-5,49) \text {, horas de exposição solar ocupacional } \\
1,76(1,04-2,99) \text { e não ocupacional 1,80 (0,98- } \\
3,29) \text { e histórico familiar 2,10 (1,13-3,93). Teste } \\
\text { de Hosmer-Lemeshow, p = 0,97. Acurácia 70\% } \\
\text { (IC 95\% 63-76). }\end{array}$ \\
\hline AUTOR & REVISTA & $\begin{array}{l}\mathbf{V}^{\circ} / \mathbf{N}^{\circ} / \\
\text { ANO }\end{array}$ & $\begin{array}{l}\text { TIPO DE } \\
\text { ESTUDO }\end{array}$ & OBJETIVO PRINCIPAL & PRINCIPAIS RESULTADOS \\
\hline $\begin{array}{l}\text { Rizzatti K, } \\
\text { Schneider IJC, } \\
\text { d'Orsi E. }\end{array}$ & $\begin{array}{l}\text { Epidemiologia e } \\
\text { Serviços de } \\
\text { Saúde. }\end{array}$ & $\begin{array}{l}\text { Volume } 20, \\
\text { número } 4, \\
\text { ano } 2011 .\end{array}$ & $\begin{array}{l}\text { Descritivo, } \\
\text { Transversal. }\end{array}$ & $\begin{array}{l}\text { Descrever as características } \\
\text { de exposição e medidas de } \\
\text { proteção solar contra câncer } \\
\text { da pele no município de } \\
\text { Florianópolis, estado de Santa } \\
\text { Catarina, Brasil. }\end{array}$ & $\begin{array}{l}\text { Dentre os } 851 \text { entrevistados, } 77,1 \% \text { declararam } \\
\text { se expor ao Sol. A exposição solar foi mais } \\
\text { freqüente entre homens, jovens, solteiros e } \\
\text { fisicamente ativos. Entre as medidas de proteção } \\
\text { solares adotadas pela população exposta ao Sol, } \\
\text { a mais utilizada foi o filtro solar ( } 36,7 \% \text { das } \\
\text { mulheres e } 10,5 \% \text { dos homens). A utilização de } \\
\text { filtro solar foi positivamente associada à } \\
\text { escolaridade. }\end{array}$ \\
\hline
\end{tabular}




\begin{tabular}{|c|c|c|c|c|c|}
\hline $\begin{array}{l}\text { Yong AR, } \\
\text { Claveau J, Rossi } \\
\text { AB. }\end{array}$ & $\begin{array}{l}\text { Journal of the } \\
\text { American } \\
\text { Academy of } \\
\text { Dermatology }\end{array}$ & $\begin{array}{l}\text { Volume } 76, \\
\text { Número 3, } \\
\text { ano } 2017 .\end{array}$ & $\begin{array}{l}\text { Analítico, } \\
\text { observacional, } \\
\text { coorte. }\end{array}$ & $\begin{array}{l}\text { Demonstrar o papel de } \\
\text { protetores solares na } \\
\text { prevençãa de ceratoses } \\
\text { actínicas, carcinomas de } \\
\text { células escamosas, nevos e } \\
\text { melanomas. As proteções } \\
\text { solares também impedem a } \\
\text { fotoimunossupressão e sinais } \\
\text { de fotoenvejamento. }\end{array}$ & $\begin{array}{l}\text { Os benefícios clínicos dos protetores solares } \\
\text { foram demonstrados em ensaios controlados } \\
\text { randomizados. Existe uma necessidade de uma } \\
\text { padronização mundial desses métodos para } \\
\text { evitar mal-entendidos e confusões entre os } \\
\text { usuários de protetores solares. }\end{array}$ \\
\hline Kim IK, He YY. & Science Direct. & $\begin{array}{l}\text { Volume } 1, \\
\text { ano } 2014 .\end{array}$ & $\begin{array}{l}\text { Analítico, } \\
\text { observacional, } \\
\text { coorte. }\end{array}$ & $\begin{array}{l}\text { Discutir caminhos que } \\
\text { regulam o reparo do dano do } \\
\text { DNA e a regulação do } \\
\text { processo inflamatório, o } \\
\text { crosstalk com o reparo do } \\
\text { DNA, levando } \\
\text { potencialmente a } \\
\text { carcinogênese da pele não } \\
\text { melanoma. }\end{array}$ & $\begin{array}{l}\text { O excesso de exposição à radiação solar UVB é } \\
\text { um fator de risco importante para o câncer de } \\
\text { pele, resultando em dano e inflamação do DNA. } \\
\text { O papel da inflamação na carcinogênese } \\
\text { induzida por UV tornou-se um princípio } \\
\text { estabelecido. Destacam-se os avanços recentes } \\
\text { em dois desses processos moleculares } \\
\text { fundamentais que resultam em carcinogênese da } \\
\text { pele mediada por UV: reparo e inflamação do } \\
\text { dano do DNA. }\end{array}$ \\
\hline AUTOR & REVISTA & $\begin{array}{l}\text { V\%/ No/ } \\
\text { ANO }\end{array}$ & $\begin{array}{l}\text { TIPO DE } \\
\text { ESTUDO }\end{array}$ & OBJETIVO PRINCIPAL & PRINCIPAIS RESULTADOS \\
\hline $\begin{array}{l}\text { Agbai ON, } \\
\text { Buster K, } \\
\text { Sanchez M, } \\
\text { Hernandez C, } \\
\text { Kundu RV, } \\
\text { Chiu M, et al. }\end{array}$ & $\begin{array}{l}\text { Journal of the } \\
\text { American } \\
\text { Academy of } \\
\text { Dermatology. }\end{array}$ & $\begin{array}{l}\text { Volume } 70, \\
\text { número } 4, \\
\text { ano } 2014 .\end{array}$ & $\begin{array}{l}\text { Descritivo - } \\
\text { Revisão } \\
\text { bibliográfica . }\end{array}$ & $\begin{array}{l}\text { Promover estratégias de } \\
\text { prevenção do câncer de pele } \\
\text { para todos os pacientes, } \\
\text { independentemente da origem } \\
\text { étnica e do status } \\
\text { socioeconômico, para levar a } \\
\text { um diagnóstico e tratamento } \\
\text { oportunos. }\end{array}$ & $\begin{array}{l}\text { Quando o câncer de pele ocorre em não brancos, } \\
\text { ele geralmente se apresenta em estágio mais } \\
\text { avançado e, portanto, o prognóstico é pior em } \\
\text { comparação com os pacientes brancos. A } \\
\text { promoção das práticas de fotoproteção pode } \\
\text { reduzir outros efeitos adversos da exposição ao } \\
\text { ultravioleta, incluindo fotoenvelhecimento e } \\
\text { distúrbios de pigmentação relacionados ao }\end{array}$ \\
\hline
\end{tabular}

REFACER v. 6, n. 2, 2017. ISSN - 2317-1367 


\begin{tabular}{|c|c|c|c|c|c|}
\hline & & & & & ultravioleta. \\
\hline $\begin{array}{l}\text { Kütting B, } \\
\text { Drexler H. }\end{array}$ & $\begin{array}{l}\text { International } \\
\text { Archives of } \\
\text { Occupational } \\
\text { and } \\
\text { Environmental } \\
\text { Health. }\end{array}$ & $\begin{array}{l}\text { Volume } 83 \text {, } \\
\text { número } 8, \\
\text { ano } 2010 .\end{array}$ & $\begin{array}{l}\text { Revisão } \\
\text { sistemática }\end{array}$ & $\begin{array}{l}\text { Fornecer uma visão geral do } \\
\text { câncer de pele com foco } \\
\text { especial na preocupação } \\
\text { ocupacional e dar } \\
\text { recomendações baseadas em } \\
\text { evidências para uma } \\
\text { prevenção efetiva no local de } \\
\text { trabalho. }\end{array}$ & $\begin{array}{l}\text { A biologia tumoral do câncer de pele é } \\
\text { divergente: queimaduras severas de bolhas } \\
\text { correspondentes a exposições UV intensas } \\
\text { intermitentes estão associadas a um risco } \\
\text { aumentado de melanoma e carcinoma } \\
\text { basocelular (BCC); Considerando que o risco } \\
\text { de carcinoma de células escamosas (SCC) e } \\
\text { queratoses actínicas (AK) está fortemente } \\
\text { associado à exposição UV crônica. Vários } \\
\text { ensaios clínicos evidenciam que o uso } \\
\text { prolongado de protetor solar impede a } \\
\text { aparência de câncer de pele não melanóico, } \\
\text { como AK e SCC, mas não de BCC. }\end{array}$ \\
\hline
\end{tabular}

